\title{
STRESS FREE VERSUS HADER BARS FOR IMMEDIATELY LOADED TWO-IMPLANT RETAINED MANDIBULAR OVERDENTURES. A ONE-YEAR RANDOMIZED TRIAL EVALUATING MARGINAL BONE LOSS AND PATIENT SATISFACTION
}

\author{
Ahmad Fathalla Shawky*
}

\begin{abstract}
Objectives: The aim of this study was to compare marginal bone loss and patient satisfaction with stress free implant bar (SFI bar) and Hader bar used for immediately loaded two-implant retained mandibular overdentures

Material and methods: Ten edentulous patients with unsatisfactory experience of conventional mandibular dentures due to atrophied mandibular ridge were randomly assigned to 2 groups and received new conventional dentures. After 2-month adaptation period, 2 implants were inserted in the canine regions of the mandible using computer guided surgery and the flapless approach. Implants were connected with Hader bar (group 1) or SFI bar (group 2) and were loaded by mandibular overdentures within 3 days after implant placement. Marginal bone loss was evaluated at baseline, 6, and 12 months later using cone beam CT. Patient satisfaction with conventional dentures and implant overdentures was measured using questionnaire based on visual analogue scale (VAS)
\end{abstract}

Results: Marginal bone loss increased significantly from 6months to 12 months for both groups. Hader bar showed significant higher bone loss than SFI bar after 6 months $(p=.001)$ and 12 months ( $\mathrm{p}<.001)$. For both groups, implant overdentures recorded significant higher satisfaction for all tested parameters (except ease of cleaning) compared to conventional dentures. SFI bar recorded significant higher satisfaction compared to natural dentition, satisfaction with retention, stability, ease of cleaning, ease of chewing than Hader bar.

Conclusion: Within the limitations of this study, SFI bar is a beneficial attachment for immediately loaded 2-implant retained overdenture as it was associated with reduced marginal bone loss and increased patient satisfaction compared to Hader bar.

KEYWORDS: bar, implant overdenture, bone loss, immediate landing and patient satisfaction.

\footnotetext{
* Associate Professor of Removable Prosthodontics, Faculty of Dentistry Beni- Suef University
} 


\section{INTRODUCTION}

Edentulous patients with conventional dentures constructed on severely resorbed alveolar mandibular bone usually had several problems ${ }^{1}$ especially in older age due maladaptive experience ${ }^{2,3}$. Subsequently, these subjects complained from reduced retention and stability, reduced oral function and psychosocial problems may arise $e^{4,5}$. It is considered that the placement of 2 implants and the fabrication of an implant-retained overdenture is the standard of care for managing problems of mandibular dentures ${ }^{6}$. In patients with mandibular atrophy, the type of attachment may play a crucial role in success of prosthetic rehabilitation. In such patients, attachments that provide horizontal stability such as bars and telescopic crowns are preferred over other attachments ${ }^{7}$. Bar attachments offer several advantages compared to unsplinted attachments when used for atrophied ridges such as load sharing between implants, reduction of lateral and torqueing forces ${ }^{8,9}$, increased lateral and horizontal stability ${ }^{10}$, increased retention, lower incidence of prosthetic complications ${ }^{11}$ and ability to be used with non-parallel implants ${ }^{12}$. Furthermore, the bars are able to reduce micromotion at the boneimplant interface which enhance osseointegration of immediately loaded implants ${ }^{13}{ }^{14}$. In contrast, nonsplinted implants are subjected to higher forces which increase micromotion in bone around implants together with reduced bone support area, thus interfering with early healing of immediately loaded implants ${ }^{14}$. Moreover, bar attachment is indicated to splint multiple short implants used with atrophied ridge (due to insufficient bone height) and distribute the stress between short implants to avoid excessive overloading of each implant and increased bone resorption. ${ }^{15,16}$. However, the disadvantages of bars include more complex laboratory procedures, increased costs, lack of passive $\mathrm{fit}^{17}$, the need of vertical restorative space ${ }^{18}$, and the complicated oral hygiene procedure ${ }^{19}$
The conventional used bars for 2 implant overdentures include oval or round bars (bar joint) that allow both vertical and rotational movements (stress breaking retention mechanism) to reduce load transmitted to the implants during mastication as denture rotate around the hinge axis connecting the implants ${ }^{20}$. Bar joint include round (Hader bars), egg shaped (Dolder bar ${ }^{21}$ Hader bar joints that consists of a key-hole shaped male bar resin pattern, Teflon fabricating rider and female nylon rider clip ${ }^{22}$. It is simple, has low profile, can be casted using several metal alloys, and had plastic clips that is easily replaceable when retention decreases and cost effective than metal clips ${ }^{11}$. In the last decade, stress free-implant bar (SFI bar, Cendres+Metaux SA) was introduced as a readymade precise round bar that allow chair-side adaption for immediate loading protocol ${ }^{23}$. This bar connects implants with no soldering or laserwelding. This allows construction of a passive-fit bar $^{24}$ with reduced corrosion ${ }^{25}$. Moreover, this bar can be used with individual implant angulations up to $15^{\circ 26}$. The immediate loaded overdenture with SFI-Bar is indicated especially in patients with a severely resorbed edentulous mandible. ${ }^{27}$ It consists of 2 or 4 ball joints that are connected to implant adapters by screws and tube bar. The length of the tube bar can be adjustable according to the interimplant distance. The bar is supplied with 2 types of female part, the E-clips (Elitor precious metal alloy) and the T-clips (all titanium grade IV with nylon inserts ${ }^{24}$. Despite these several advantages, longterm success of this system still has to be proved in randomized clinical studies ${ }^{26}$ that compared it to the conventional used bars.

The immediate loading of the implants with implant-overdentures reduces surgical and prosthetic visits, increases patient satisfaction and improves mastication and aesthetics ${ }^{28}$. Maintenance of stable crestal bone level is mandatory for a successful long-term outcome of dental implants ${ }^{29}$. Long-term studies have shown that crestal bone loss occurs 
during the first year in function ${ }^{30}$ and may be due to infection (peri-implantitis), surgery or implant loading ${ }^{31}$. Patient-reported outcome is affected by prosthesis type and affect the decision of selecting appropriate type of attachment ${ }^{32}$. The perception more commonly used for the assessment of implant treatment in edentulous patients is oral health-related quality of life (OHRQoL). Patient satisfaction can also be evaluated through quantification of patients' opinion regarding the overdentures ${ }^{33}$. Although marginal bone loss of ball attachments was found to be significantly higher than bar attachments for immediate loaded 2 implants by mandibular overdentures $^{34}$, the evaluation of marginal bone loss with different bar designs for immediate loaded implants in patients with atrophied ridge was not investigated. The aim of the present randomized controlled trial was to compare marginal bone loss and patient satisfaction with stress free implant bar and conventional Hader bar for immediately loaded two-implant retained mandibular overdentures. The null hypothesis was that there will be no difference in marginal bone loss and patient satisfaction between the tested attachments.

\section{MATERIAL AND METHODS}

\section{Patient enrollment and study design}

Ten edentulous patients ( 5 men and 5 women) with unsatisfactory experience of conventional mandibular dentures (mean age of 59 year) due to atrophied mandibular ridge were selected for this trial. The duration of wearing the old mandibular dentures ranged from 1 to 3 years. The inclusion criteria include patients with healthy mucosa, sufficient interarch space, class III -V resorption in the inter-foraminal region of the mandible (according to Cawood and Howell ${ }^{35}$ ), and good bone quality (classes 1-3 according to Lekholm and Zarb) ${ }^{36}$. All patients complained from reduced stability and insufficient retention of their mandibular dentures. Exclusion criteria included: V-shaped mandibular arch form, Patients with a history of cardiovascular complications, diabetic patients, patients with liver dysfunction, blood dyscrasias or underwent anticoagulant therapy, patients with osteoporosis or long-term radiation therapy. The protocol and objectives of the study were described to all participants before obtaining an informed consent. The study was conducted according to principles stated in the Helsinki Declaration and approved by the Faculty ethical committee (approval no. \#FDBSUREC/12052019/SA).

The patients were asked to participate in this study without prior knowledge of which type of attachments they were going to receive. Patients were randomly allocated into 2 groups using a simple randomization procedure (generated in Excel sheet) to ensure no difference in sex distribution (using chi square test) in each group: Group 1 (Hader bar, control) in which the overdentures were connected to the implants with Hader bar attachments. Group 2 (SFI bar, test) in which the overdentures were connected to the implants with stress free implant bar attachments. Group 1 had 3 males and 2 females and group 2, had 2 males and 3 females.

\section{Surgical and prosthetic procedures}

For all participants, new upper and lower complete dentures were made using bilateral balanced occlusal concept and semi anatomic acrylic artificial teeth. After 2-month adaptation period, gutta perchae markers were embedded in the polished surface of the mandibular denture at labial, vestibular and lingual flanges. Dual scan protocol was followed using cone beam CT (CBCT, i-CAT, Imaging Sciences International ISI, Pennsylvania, and USA). The first scan was made while patients wore their dentures and the second scan was made to the denture alone. The data sets of the double scans were overlapped then the acquired images were loaded into 3-D image treatment planning software (On Demand). According to the CT scan, the implants were virtually planned in the canine areas. 
Based on this plan, stereolithographic surgical guide was constructed using prototyping technique for each participant. Virtual model planning software was used to define the sites for implant placement and anchor pins for the surgical guide. A mucosal supported stereolithographic surgical template (fig 1a) with 2 sleeves positioned over proposed implant sites was constructed using 3D printing technology (In2Guide). The surgery was made according the flapless protocol under local anesthesia using partial guided protocol. Two implants ((Neoss Ltd., Harrogate, England) were inserted using the surgical guide and the universal surgical kit (In2Guide, Universal Kit Cybermed Inc.) supplied with the mucosal supported stereolithographic surgical template to be used during osteotomy preparation (fig 1b). This kit includes hand drill sleeves with successive increasing diameters that fit the template holes (in the same diameter of sleeves). The hand sleeves were used during consecutive drilling procedures with surgical guide to accommodate successive increasing in drill diameter. The template was stabilized in the patient's mouth by a rubber base interocclusal record and fixed to the mandibular bone using anchor pins. The minimum torque at implant placement was $40 \mathrm{Ncm}$ to permit immediate loading of the implants ${ }^{37}$. All patients were administered postoperative antibiotics (amoxicillin and clavulanic acid), analgesics, and mouth rinse with a $0.12 \%$ chlorhexidine digluconate.

For Hader bar (control group), long impression transfer copings with long screws were threaded into the implants ${ }^{38}$. The copings were splinted with Duralay resin (Duralay, Reliance Dental MFG Co, Worth, IL, USA). Open tray impression technique was made. The light-body material was injected around the impression copings and the impression was completed with heavy body material in stock tray. Implant analogues were attached to the impression coping with the long fixation screw and the final impressions were poured with stone (ZETA, Orthodontic Stone; WhipMix. Corp, Louisville, KY). Bar abutments were screwed into the implant analogues and the implants were connected with a resilient Hader bar (OT bar multiuse ${ }^{\circledR}$, RHEIN 83, Italy) leaving $2 \mathrm{~mm}$ clearance space between the bar and the ridge. Plastic pattern of the bar was luted to the plastic bar abutments with sticky wax and the assembly was sprued, invested, casted into cobaltchromium alloy. The bar was tried in for passivity in patient mouth using single screw test (fig 2a). If the bar was not passive, it was sectioned, reassembled and soldered.

For group 2, the implant adapters (bar abutments) of the SFI-Bar ${ }^{\circledR}($ Cendres + Metaux, Biel/Bienne, Switzerland) were screwed to the implants and tube bars were screwed to the implant adapter on using

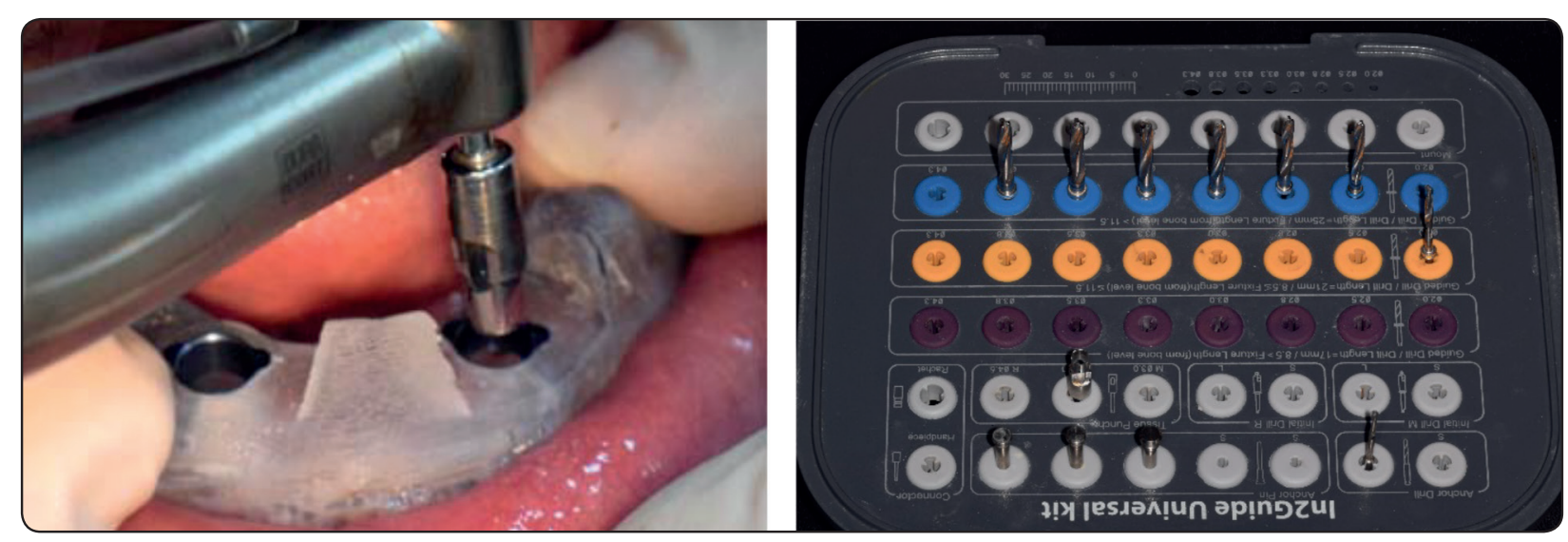

Fig. (1) A; The steolithographic guide, B, The universal surgical kit 
screw driver. The ball joint on one side was fixed with screws. The tube bar and tube bar gauge on the other side was slid onto the pin of the ball joint until the gauge could be fitted onto the other implant adapter and screwed. The tube bar was sectioned with a disc. The shortened tube bar was slid onto the pin and retightened tension-free. For both groups, bars were tightened in place intraorally with a torque wrench $(25 \mathrm{~N} / \mathrm{cm})$. Two plastic clips (red, light retention) were inserted in the metal housings and fastened to the bar intraorally. Sufficient relief in the fitting surface of the mandibular dentures was made using disclosing media till no contact was present between the denture and the sleeves of the bars. The space under and around the bars was blocked out with wax. The metal housings and retentive clips were picked up intraorally with selfcure acrylic resin to ensure passive fit (fig $2 b$ and fig $3 b$ for group 1 ang group 2 respectively). The overdentures were delivered to the patients within 3 days after implant placement with emphasis on oral hygiene instructions, and soft diet and 2-weeks regular recall visits for adjustments were scheduled all over the study period

\section{Implant related outcomes}

\section{Marginal bone loss}

For each participant, Cone beam computerized tomography (i-CAT device; Imaging Sciences Intl) was made at base line, 6 months $(6 \mathrm{~m})$, and 12 months (12m) after denture delivery. The marginal bone resorption was measured at mesial,

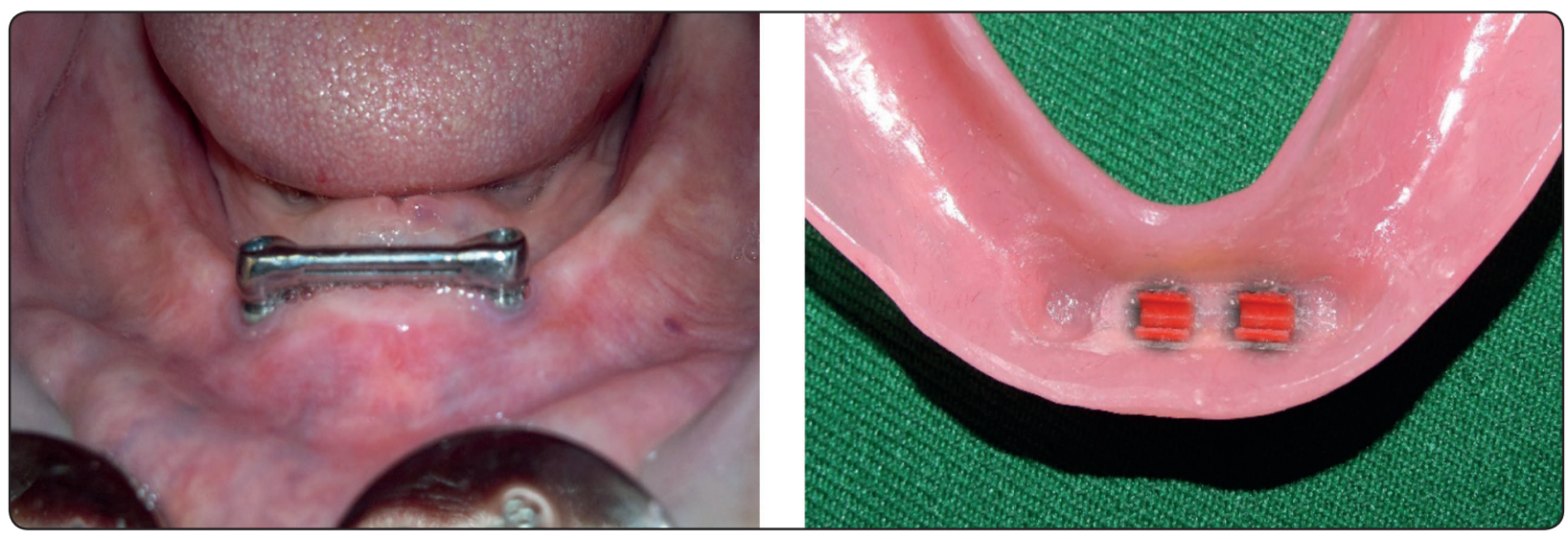

Fig (2) group I (Hader bar group, control): A. Bar in the patient mouth. B. Fitting surface of the bar

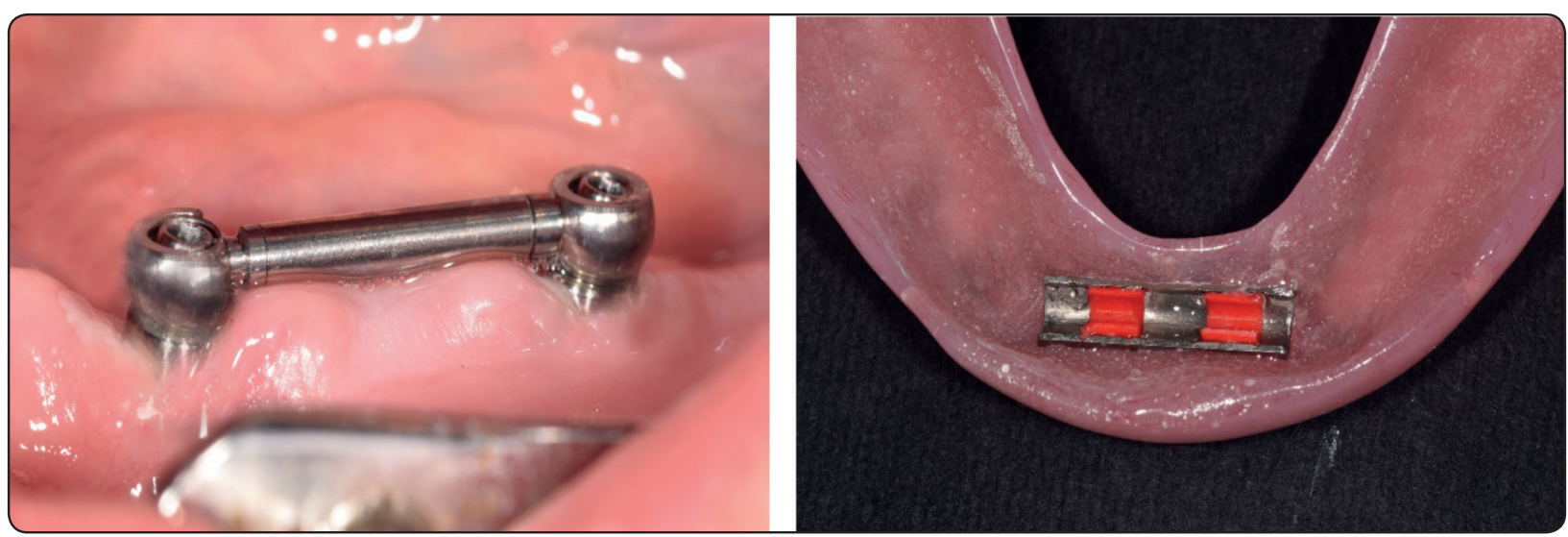

Fig 3: group 2 (SFI bar group, test): A. Bar in the patient mouth. B. Fitting surface of the bar 
distal, buccal and lingual surface of each implant and the mean was subjected to statistical analysis. Mesial and distal peri-implant bone resorption was measured at the panoramic images of the CT. Buccal and lingual bone resorption was calculated at cross sectional images using the accompanied software (OnDemand3DApp Software; CyberMed Inc.) (fig6). To calculate marginal bone resorption, the vertical distance from implant abutment junction (point A) to the bone contact with implant (point B) was measured to give bone level ${ }^{39}$. Bone loss was calculated by subtracting bone levels at $6 \mathrm{~m}$ and $12 \mathrm{~m}$ from bone levels at base line. The bone loss measurement for right and left implants were averaged since no statistically significant difference was noted between right and left bone measurements for each patient (using Mann Whitney test).

\section{Patient satisfaction}

Patient satisfaction was measured using questionnaire based visual analogue scale (VAS) with conventional dentures (before implant treatment, base line, T0), after a 3-month period of wearing the bar-retained overdentures (to enhance neuromuscular adaptation) (T1). ${ }^{40,41}$ Subjects were asked to draw a vertical line anywhere across a horizontal one (on a scale from 0 to $100 \mathrm{~mm}$ ) at the point that best represented their perceptions.

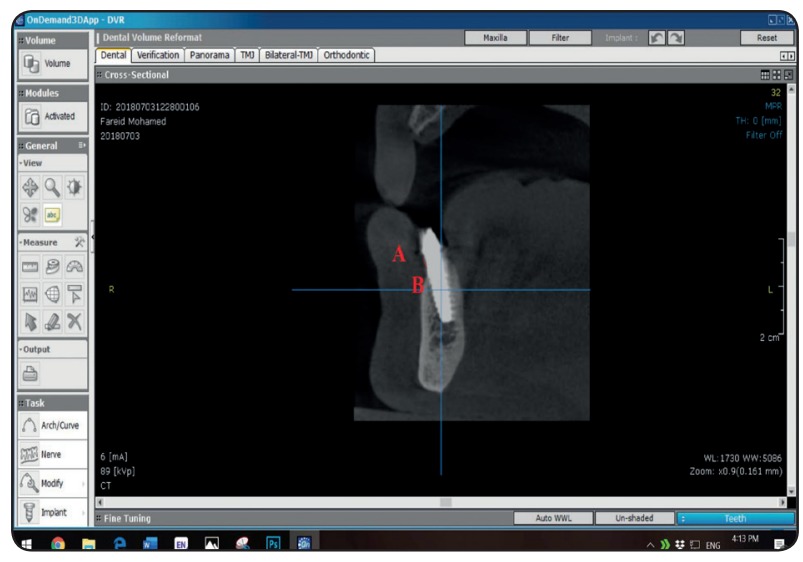

Fig. (4) Bone height measurement using CT cross sectional images
Questions included are general satisfaction, satisfaction compared to natural teeth, retention, stability, occlusion, comfort, ease of cleaning, speaking, chewing, food choice, quality of meals, and esthetics (fig 5).

\begin{tabular}{|c|c|}
\hline 1) & $\begin{array}{l}\text { In general, are you satisfied with your mandibular } \\
\text { prosthesis? }\end{array}$ \\
\hline 2) & $\begin{array}{c}\text { In comparison with a natural dentition, are you } \\
\text { satisfied with your mandibular prosthesis? }\end{array}$ \\
\hline 3) & $\begin{array}{l}\text { Retention: Are you satisfied with the retention of } \\
\text { your mandibular prosthesis? }\end{array}$ \\
\hline 4) & $\begin{array}{l}\text { Stability: Are you satisfied with the stability of your } \\
\text { mandibular prosthesis? }\end{array}$ \\
\hline 5) & $\begin{array}{l}\text { Occlusion: Are you satisfied with the occlusion of } \\
\text { your prostheses? }\end{array}$ \\
\hline 6) & $\begin{array}{l}\text { Comfort: Is your mandibular prosthesis } \\
\text { comfortable? }\end{array}$ \\
\hline 7) & $\begin{array}{l}\text { Ease of cleaning: Is it difficult to clean your } \\
\text { mandibular prosthesis? }\end{array}$ \\
\hline 8) & $\begin{array}{l}\text { Ease of speaking: Is it difficult to speak with your } \\
\text { prostheses? }\end{array}$ \\
\hline 9) & $\begin{array}{l}\text { Ease of chewing: Is it difficult to chew fresh white } \\
\text { bread? }\end{array}$ \\
\hline 10) & $\begin{array}{c}\text { Quality of bolus: Are the pieces of fresh white } \\
\text { bread well-chewed before swallowing? }\end{array}$ \\
\hline 11) & $\begin{array}{l}\text { Esthetics: Are you satisfied with the appearance of } \\
\text { your mandibular prosthesis? }\end{array}$ \\
\hline
\end{tabular}

Fig. (5) Patient satisfaction questionnaire

\section{Statistical analysis}

The data were explored for normality of distribution. The data was non-parametric and violated the normal distribution. Descriptive statistics of marginal bone loss and patient satisfaction scores were presented as median (Med), minimum (mini), and maximum (maxi). The difference in marginal bone loss between six and 12 months after insertion and difference in patient 
satisfaction with conventional dentures and implant overdentures was detected using Wilcoxon signed ranks test. Mann Whitney test was used to compare outcomes between groups. The data were analyzed using SPSS ${ }^{\circledR}$ software version 25 (SPSS Inc., Chicago, IL, USA). P-values $<0.05$ were considered to be significant.

\section{RESULTS}

Due to the short period of evaluation, all participants completed the examinations without dropouts. No implant failure occurred in both groups after loading yielding $100 \%$ survival rate. Two independent examiners evaluated marginal bone height changes and the data were compared for them using alpha Cronbach test to evaluate interexaminer reliability with correlation coefficient $>.80$, therefore the data was considered reliable.

Comparison of marginal bone loss in $\mathrm{mm}$ between observation times and between groups is presented in table 1. Marginal bone loss increased significantly from 6 months to 12 months for Hader $(\mathrm{p}=.025)$ and SFI (.030) bars respectively. There was a significant difference in marginal bone loss between groups. Hader bar showed significant higher bone loss than SFI bar after 6 months $(\mathrm{p}=.001)$ and 12 months $(\mathrm{p}<.001)$ of overdenture delivery.

Comparison of medians of VAS questionnaire is presented in table 2. For both groups, implant overdentures recorded significant higher satisfaction for all tested parameters (except ease of cleaning) as compared to conventional dentures. No difference in all tested questions between the 2 groups regarding the conventional dentures. SFI bar recorded significant higher satisfaction compared to natural dentition ( $\mathrm{p}=.007)$, satisfaction with retention $(\mathrm{p}=.010)$, stability $(\mathrm{p}=.020)$, ease of cleaning $(\mathrm{p}=.035)$, ease of chewing $(\mathrm{p}=.007)$ than Hader bar. No significant difference between the 2 groups was noted regarding general satisfaction, occlusion, comfort, ease of speaking, quality of bolus, and esthetics.

\section{DISCUSSION}

Overall, the null hypothesis was rejected since there were significant differences in marginal bone loss and patient satisfaction between the 2 groups. In this study, the authors used the Hader bar design as a control for SFI bar due to the similarity of both bars design. The Hader bar has a key hole design and the top of the bar is rounded in cross section. Similarly, SFI bar has rounded cross section. In contrast Dolder bar designs have oval cross section. Although SFI bar has a metal gold rounded clip, plastic clips were chosen as it provides more resiliency and act as shock absorber than metal clips to reduce the load transferred to the implants and decrease implant micromotions which is a crucial factor due to immediate loading protocol utilized in this study. This is another explanation for choosing Hader bar as it has plastic clips, while Dolder bar

TABLE (1) Comparison of marginal bone loss in mm [median (minimum-maximum)] between observation times and between groups

$\begin{array}{cccc} & \begin{array}{c}6 \text { months after insertion } \\ \text { Hader }\end{array} & .72 \text { months after insertion } & \begin{array}{c}\text { Wilcoxon signed ranks test } \\ (\mathrm{p} \text { value) }\end{array} \\ \text { SFI } & .41(.3-.5) & .92(.8-1.3) & .025^{*} \\ \text { Mann Whitney (p value) } & .001^{*} & .63(.4-.7) & .030^{*}\end{array}$

*P is significant at $5 \%$ 
TABLE (2) Estimated medians in mm [median (minimum-maximum)] associated with each parameter based on VAS Questionnaire and comparisons between groups and observations

\begin{tabular}{|c|c|c|c|c|}
\hline & Group & $\begin{array}{l}\text { Conventional denture } \\
\text { median(mini-maxi) }\end{array}$ & $\begin{array}{l}\text { Implant overdentures after } \\
\qquad 3 \text { months } \\
\text { median(mini-maxi) }\end{array}$ & $\begin{array}{l}\text { Wilcoxon signed } \\
\text { ranks test ( } \mathrm{p} \text { value) }\end{array}$ \\
\hline \multirow[t]{3}{*}{ 1.General satisfaction } & Hader & $65(55-74)$ & $88(80-93)$ & $.005^{*}$ \\
\hline & SFI & $68(57-77)$ & $90(82-95)$ & $.004 *$ \\
\hline & Mann Whitney (p value) & .74 & .12 & \\
\hline \multirow[t]{3}{*}{ 2.Versus dentition } & Hader & $25(15-30)$ & $79(73-86)$ & $.001 *$ \\
\hline & SFI & $28(17-33)$ & $85(80-91)$ & $.001 *$ \\
\hline & Mann Whitney ( $p$ value) & .58 & $.007 *$ & \\
\hline \multirow[t]{3}{*}{ 3. Retention } & Hader & $15(11-24)$ & $80(75-88)$ & $.001 *$ \\
\hline & SFI & $20(15-28)$ & $93(84-96)$ & $.002 *$ \\
\hline & Mann Whitney ( $p$ value) & .66 & $.010 *$ & \\
\hline \multirow[t]{3}{*}{ 4. Stability } & Hader & $25(19-31)$ & $83(76-89)$ & $.002 *$ \\
\hline & SFI & $30(23-36)$ & $95(86-98)$ & $.003 *$ \\
\hline & Mann Whitney ( $p$ value) & .23 & $.020 *$ & \\
\hline \multirow[t]{3}{*}{ 5. Occlusion } & Hader & $20(10)$ & $90(85-94)$ & $.004 *$ \\
\hline & SFI & $22(7)$ & $91(84-95)$ & $.003 *$ \\
\hline & Mann Whitney ( $p$ value) & .84 & .85 & \\
\hline \multirow[t]{3}{*}{ 6. Comfort } & Hader & $15(10-20)$ & $90(83-94)$ & $.010 *$ \\
\hline & SFI & $19(14-23)$ & $93(84-93)$ & $.009 *$ \\
\hline & Mann Whitney ( $\mathrm{p}$ value) & 1.0 & .31 & \\
\hline \multirow[t]{3}{*}{ 7. Ease of cleaning } & Hader & $82(11.5)$ & $79(74-85)$ & .31 \\
\hline & SFI & $89(6.5)$ & $90(84-95)$ & .23 \\
\hline & Mann Whitney ( $p$ value) & 1.0 & $.035 *$ & \\
\hline \multirow[t]{3}{*}{ 8. Ease of speaking } & Hader & $60(50-69)$ & $88(82-94)$ & $.012 *$ \\
\hline & SFI & $63(54-68)$ & $89(81-93)$ & $.015 *$ \\
\hline & Mann Whitney ( $p$ value) & .24 & .56 & \\
\hline \multirow[t]{3}{*}{ 9. Ease of chewing } & Hader & $19(11-27)$ & $84(81-89)$ & $.009 *$ \\
\hline & SFI & $20(12-26)$ & $92(85-95)$ & $.007 *$ \\
\hline & Mann Whitney ( $p$ value) & .48 & $.007 *$ & \\
\hline \multirow[t]{3}{*}{ 10. Quality of bolus } & Hader & $17(15-20)$ & $94(89-95)$ & $.006 *$ \\
\hline & SFI & $19(14-22)$ & $94(88-94)$ & $.008 *$ \\
\hline & Mann Whitney (p value) & .11 & .85 & \\
\hline \multirow[t]{3}{*}{ 11. Esthetics } & Hader & $65(58-69)$ & $81(78-85)$ & $.011 *$ \\
\hline & SFI & $63(59-70)$ & $83(79-86)$ & $.012 *$ \\
\hline & Mann Whitney ( $p$ value) & .29 & .53 & \\
\hline
\end{tabular}

*P is significant at 5\% 
has metal clips which may transfer more load to the implants. Moreover, plastic clips are advantageous because they are more easily replaced if retention has slackened and usually less expensive than metal. In addition, plastic clips may produce less wear of the metal bar than metal clips ${ }^{42}$.

The use of cone beam computerized tomography in evaluation of marginal bone loss for implant overdentures has been reported in a previous study ${ }^{39}$ with acceptable precision. This technique allow monitoring of the buccal and lingual bone levels around implants and has no magnification or distortion such as the 2 dimensional peri-apical or radiographic images ${ }^{43}$

No implant failure occurred in both groups after loading yielding $100 \%$ survival rate. This high survival rate may be attributed to splinting of the implants with bar that may distribute the load to the implants, reduce implant micromotions, transmit load vertically to the implants and reduce lateral movements which is very helpful in case of immediate loading ${ }^{13}$. The amount of bone loss in both groups ranged between $.41 \mathrm{~mm}$ to $.92 \mathrm{~mm}$ after one year which is still within the normal range of bone loss noted in the literature ${ }^{44}$. The reduced bone loss could be attributed to the splitting of the implants and the fact that these implants are installed in the dense basal bone of the mandible due to mandibular atrophy ${ }^{39}$. This bone is associated with increased implant stability and reduced bone loss.

Marginal bone loss increased significantly from 6 months to 12 months for both groups. The bone loss could be attributed to maturation of bone after fixture installation and adaptation of bone to resist occlusal loads ${ }^{44}$. Hader bar showed significant higher bone loss than SFI bar after 6 months and 12 months. This could be attributed to several reasons. Firstly, the rough surface of the Hader bar produced by casting nodules, finishing and polishing may enhance plaque accumulation, complicate oral hygiene, enhance per-implant mucosal inflammation and bone loss. The increased plaque accumulation in the Hader group, although not measured in this study, was clinically noted compared to SFI bar group. In contrast, SFI bar has a prefabricated smooth surface which prevent plaque accumulation, and enhance self-cleaning of the bar and oral hygiene. Secondly, the total height of the Hader bar is more than the height of the SFI bar. This increased height may cause vertical cantilever and increase stresses to the implant compared to SFI bar. The increased height comes from increased length of the plastic cap and prosthetic screw used with Hader bar. In contrast, the SFI bar has one screw that fix the bar joint and the bar into the implant adapter (which have the same level of mucosa). Therefore, the total vertical height decreases (about $3 \mathrm{~mm}$ from the mucosal level compared to $5 \mathrm{~mm}$ total vertical height of the SFI bar). Thirdly, and most importantly, the stressfree nature of the SFI bar ensures complete screwing of the bar without transmitting micromovements to the implants. This is a crucial factor especially in the initial healing period after immediate loading. According to the manufacturer, due to the telescopic design of the bar joints, no lateral stress is applied to the implants ${ }^{25}$. In contrast, the impression for Hader bar is usually made under impaired conditions due to wound bleeding, which can lead into inaccuracies of the master cast that may impair the passive fit of the final bar ${ }^{45}$. Furthermore, the impression may compromise wound-healing which may negatively affect bone $\operatorname{loss}^{46}$. Finally, SFI bar can tolerate implant divergence up to $15^{\circ}$ without transmitting stresses to the implants due to the nature of telescopic ball joint of the bar ${ }^{45}$. In contrast implant nonparallelism with Hader bar may increase friction of prosthetic screw during screwing the bat bar to the abutments and increase implant micromotions with non-parallel implants.

Implant overdentures recorded significant higher satisfaction for all tested parameters (except ease of cleaning) as compared to conventional dentures. This observation is not surprising and comes in 
line with results of other investigations ${ }^{5,47,48}$. This may be due to the fact that bar attachments increase the retention and stability of the dentures, improve comfort on mastication and enhance oral perception, function, and psychological factors ${ }^{49}$. The decreased stability of the conventional dentures due to high floor of the mouth in subjects with atrophied mandibular jaws will irritate thin delicate mucosa, induce patient discomfort and cause a decrease in patient satisfaction ${ }^{50}$. However, the increased mucosal coverage of the bar could enhance plaque deposition around and under the bar and abutments, which complicate oral hygiene practice ${ }^{51}$

SFI bar recorded significant higher satisfaction compared to natural dentition, satisfaction with retention, and stability than Hader bar. The acceptable retention and stability of the SFI-Bar is in line with a previous case report ${ }^{25}$. The increased retention and stability of SFI overdenture is responsible for increased satisfaction compared to natural teeth. The increased retention and stability of SFi bar compared to Hader bar may be due to the design and position of retentive plastic clips. Plastic clips of SFI bar engaging and encircling the whole rounded bar (with maximum utilization of undercuts below the bar), while clips of Hader bar engage the top round surface of the bar only so it is easily disconnected from the bar. Also casting or soldering the Hader bar may reduce the length of the retentively usable bar surfaces ${ }^{27}$, while the entire length of SFI bar may be used to increase the retention. The increased retention of the SFI bar was in line with findings of -another study ${ }^{24}$ in which the authors used plastic clips over the SFI bar and found that these clips maintain retention and need replacement after 2 to 3 years of clinical use. Also, Kobayashi, et al. ${ }^{26}$ noted that SFI-Bar exhibit higher retentive capacities than the Locatorattachment over time. However, direct comparison of the retention of the clips in this study with clips in the study of Kobayashi et al was not possible as two separate plastic clips were used in this study, while in the study of Kobayashi et al, single metal clip engaging the entire length of the bar was used.

SFI bar also was associated with increased satisfaction regarding ease of cleaning, and ease of chewing than Hader bar. The ease of cleaning could be attributed to the smooth rounded surfaces which are self-cleansing and not allow plaque accumulation compared to irregular surfaces of Hader bar as stated previously. The increased satisfaction regarding ease of chewing may be attributed to the increased retention, stability of SFI bar compared to Hader bar. The increased satisfaction with chewing with SFI bar is in line with findings of Albrecht, et al. ${ }^{45}$ who reported increased self-perceived oral function, patient satisfaction, chewing comfort or general discomfort in patients with 2 implant overdentures connected with SFI bar although a slight increase in the lingual contour of the denture was noted due to direct connection between the two implants (the bar did not follow the alveolar ridge). They attributed this to the enough vertical space under the denture to house the SFI patrix and matrix components, especially with atrophied ridge with no alteration of the denture dimension.

The limitations of the study included the small sample size, the short evaluation period, the lack of evaluation of other clinical outcomes such as plaque and gingival indices, pocket depth and implant stability. Therefore, long term randomized trials with sufficient sample size are still needed.

\section{CONCLUSION}

Within the limitation of this study, SFI bar attachment is recommended for immediately loaded 2-implant retaining mandibular overdentures as it was associated with reduced marginal bone loss and increased patient satisfaction compared to Hader bar.

Conflict of interest: There is no conflict of interest in this manuscript. 


\section{REFERENCES}

1. Hong HR, Pae A, Kim Y, Paek J, Kim HS, Kwon KR. Effect of implant position, angulation, and attachment height on peri-implant bone stress associated with mandibular twoimplant overdentures: a finite element analysis. Int J Oral Maxillofac Implants. 2012;27:e69-76.

2. Muller F, Naharro M, Carlsson GE. What are the prevalence and incidence of tooth loss in the adult and elderly population in Europe? Clin Oral Implants Res. 2007;18 Suppl 3:2-14.

3. Carlsson GE, Omar R. The future of complete dentures in oral rehabilitation. A critical review. J Oral Rehabil. 2010;37:143-56.

4. Muller F, Hernandez M, Grutter L, Aracil-Kessler L, Weingart D, Schimmel M. Masseter muscle thickness, chewing efficiency and bite force in edentulous patients with fixed and removable implant-supported prostheses: a cross-sectional multicenter study. Clin Oral Implants Res. 2012;23:144-50.

5. Awad MA, Lund JP, Shapiro SH, Locker D, Klemetti E, Chehade A, et al. Oral health status and treatment satisfaction with mandibular implant overdentures and conventional dentures: a randomized clinical trial in a senior population. Int J Prosthodont. 2003;16:390-6.

6. Thomason JM, Feine J, Exley C, Moynihan P, Muller F, Naert I, et al. Mandibular two implant-supported overdentures as the first choice standard of care for edentulous patients--the York Consensus Statement. Br Dent J. 2009;207:185-6.

7. Heckmann SM, Winter W, Meyer M, Weber HP, Wichmann MG. Overdenture attachment selection and the loading of implant and denture-bearing area. Part 1: In vivo verification of stereolithographic model. Clin Oral Implants Res. 2001;12:617-23.

8. Mericske-Stern R, Piotti M, Sirtes G. 3-D in vivo force measurements on mandibular implants supporting overdentures. A comparative study. Clin Oral Implants Res. 1996;7:387-96.

9. Misch CE, Wang HL, Misch CM, Sharawy M, Lemons J, Judy KW. Rationale for the application of immediate load in implant dentistry: part II. Implant Dent. 2004; 13:310-21.

10. Spiekermann H. Implantology. In: Rateitschak, K.H. \& Wolf, H.F., eds. Color Atlas of Dental Medicine. New York: Thieme Medical Publishers. 1995:164.
11. Naert I, Gizani S, Vuylsteke M, Van Steenberghe D. A 5 -year prospective randomized clinical trial on the influence of splinted and unsplinted oral implants retaining a mandibular overdenture: prosthetic aspects and patient satisfaction. J Oral Rehabil. 1999;26:195-202.

12. Carpentieri JR. Clinical protocol for an overdenture bar prosthesis fabricated with $\mathrm{CAD} / \mathrm{CAM}$ technology. Pract Proced Aesthet Dent. 2004;16:755-7.

13. Alfadda SA, Attard NJ, David LA. Five-year clinical results of immediately loaded dental implants using mandibular overdentures. Int J Prosthodont. 2009;22:368-73.

14. Lorenzoni M, Pertl C, Zhang K, Wegscheider WA. In-patient comparison of immediately loaded and non-loaded implants within 6 months. Clin Oral Implants Res. 2003;14:273-9.

15. Chee W, Jivraj S. Treatment planning of the edentulous mandible. Br Dent J. 2006;201:337-47.

16. Martinez-Lage-Azorin JF, Segura-Andres G, Faus-Lopez J, Agustin-Panadero R. Rehabilitation with implant-supported overdentures in total edentulous patients: A review. J Clin Exp Dent. 2013;5:e267-72.

17. Barbi FC, Camarini ET, Silva RS, Endo EH, Pereira JR. Comparative analysis of different joining techniques to improve the passive fit of cobalt-chromium superstructures. $\mathrm{J}$ Prosthet Dent. 2012;108:377-85.

18. Ahuja S, Cagna DR. Defining available restorative space for implant overdentures. J Prosthet Dent. 2010; 104:133-6.

19. Efvinol. B, Jorgeusen. D. Prosthetic for elderly. Quintessence, Publication Co. Inc.Chicago. . 1999:P233.

20. Federick DR, Caputo AA. Effects of overdenture retention designs and implant orientations on load transfer characteristics. J Prosthet Dent. 1996;76:624-32.

21. Bayer S, Komor N, Kramer A, Albrecht D, Mericske-Stern $\mathrm{R}$, Enkling N. Retention force of plastic clips on implant bars: a randomized controlled trial. Clin Oral Implants Res. 2012;23:1377-84.

22. Stoker GT, Wismeijer D, van Waas MA. An eight-year follow-up to a randomized clinical trial of aftercare and costanalysis with three types of mandibular implant-retained overdentures. J Dent Res. 2007;86:276-80.

23. Kim HY, Kim RJ, Qadeer S, Jeong CM, Shin SW, Huh JB. Immediate loading on mandibular edentulous patient with SFI Bar(R) overdenture. J Adv Prosthodont. 2011;3:47-50. 
24. Wei L, Ma Q, Qin X, Pan S. In Vitro Cyclic Dislodging Test on Retentive Force of Two Types of Female Parts of SFI-Bar. The International journal of prosthodontics. 2016;29:293-5.

25. Ha SR, Kim SH, Song SI, Hong ST, Kim GY. Implantsupported overdenture with prefabricated bar attachment system in mandibular edentulous patient. J Adv Prosthodont. 2012;4:254-8.

26. Kobayashi M, Srinivasan M, Ammann P, Perriard J, Ohkubo C, Muller F, et al. Effects of in vitro cyclic dislodging on retentive force and removal torque of three overdenture attachment systems. Clin Oral Implants Res. 2014;25:426-34

27. Kim HY, Kim RJ, Qadeer S, Jeong CM, Shin SW, Huh JB. Immediate loading on mandibular edentulous patient with SFI Bar(R) overdenture. J Adv Prosthodont. 2011;3:47-50.

28. Chiapasco M, Gatti C. Implant-retained mandibular overdentures with immediate loading: a 3- to 8-year prospective study on 328 implants. Clin Implant Dent Relat Res. 2003;5:29-38.

29. De Bruyn H, Vandeweghe S, Ruyffelaert C, Cosyn J, Sennerby L. Radiographic evaluation of modern oral implants with emphasis on crestal bone level and relevance to peri-implant health. Periodontol 2000. 2013;62:256-70.

30. Oh TJ, Yoon J, Misch CE, Wang HL. The causes of early implant bone loss: myth or science? J Periodontol. 2002;73:322-33.

31. Jemt T, Albrektsson T. Do long-term followed-up Branemark implants commonly show evidence of pathological bone breakdown? A review based on recently published data. Periodontol 2000. 2008;47:133-42.

32. Feine JS, Awad MA, Lund JP. The impact of patient preference on the design and interpretation of clinical trials. Community Dent Oral Epidemiol. 1998;26:70-4.

33. ELsyad M. A, Elgamal M, Mohammed Askar O, Youssef AlTonbary G. Patient satisfaction and oral health-related quality of life (OHRQoL) of conventional denture, fixed prosthesis and milled bar overdenture for All-on-4 implant rehabilitation. A crossover study. Clin Oral Implants Res. 2019.

34. Elsyad MA, Al-Mahdy YF, Fouad MM. Marginal bone loss adjacent to conventional and immediate loaded two implants supporting a ball-retained mandibular overdenture: a 3-year randomized clinical trial. Clin Oral Implants Res. 2012;23:496-503.
35. Cawood JI, Howell RA. A classification of the edentulous jaws. Int J Oral Maxillofac Surg. 1988;17:232-6.

36. Lekholm U, Zarb G. Patient selection and preparation. In: Branemark PI, Zarb G, Albrektsson T, eds. Tissue integrated prosthesis: osseointegration in clinical dentistry. Chicago. Quintessence Publishing Co Inc. 1985:199-209.

37. Sannino G, Bollero P, Barlattani A, Gherlone E. A Retrospective 2-Year Clinical Study of Immediate Prosthetic Rehabilitation of Edentulous Jaws with Four Implants and Prefabricated Bars. J Prosthodont. 2017; 26:387-94.

38. Zarb GA, Jansson T. Prosthodontic procedures. In: Brånemark, P.I., Zarb, G.A., Albrektsson, T. eds. Tissue Integrated Prostheses - Osseointegration in Clinical Dentistry p 251-270. 1985; Quintessence Publishing Co. Inc. Chicago, United States of America.

39. Elsyad MA, Khirallah AS. Circumferential bone loss around splinted and nonsplinted immediately loaded implants retaining mandibular overdentures: A randomized controlled clinical trial using cone beam computed tomography. J Prosthet Dent. 2016;116 741-8

40. de Albuquerque Junior RF, Lund JP, Tang L, Larivee J, de Grandmont P, Gauthier G, et al. Within-subject comparison of maxillary long-bar implant-retained prostheses with and without palatal coverage: patient-based outcomes. Clin Oral Implants Res. 2000;11:555-65.

41. Tang L, Lund JP, Tache R, Clokie CM, Feine JS. A withinsubject comparison of mandibular long-bar and hybrid implant-supported prostheses: psychometric evaluation and patient preference. J Dent Res. 1997;76:1675-83.

42. Walton JN, Ruse ND. In vitro changes in clips and bars used to retain implant overdentures. J Prosthet Dent. 1995;74:482-6.

43. Naitoh M, Hayashi H, Tsukamoto N, Ariji E. Labial bone assessment surrounding dental implant using conebeam computed tomography: an in vitro study. Clin Oral Implants Res. 2012;23:970-4.

44. Albrektsson T, Zarb G, Worthington P, Eriksson AR. The long-term efficacy of currently used dental implants: a review and proposed criteria of success. Int $\mathrm{J}$ Oral Maxillofac Implants. 1986;1:11-25.

45. Albrecht D, Ramierez A, Kremer U, Katsoulis J, MericskeStern R, Enkling N. Space requirement of a prefabricated bar on two interforaminal implants: a prospective clinical study. Clin Oral Implants Res. 2015;26:143-8. 
46. Moy PK, Medina D, Shetty V, Aghaloo TL. Dental implant failure rates and associated risk factors. The International journal of oral \& maxillofacial implants. 2005;20:569-77.

47. Naert I, Alsaadi G, Quirynen M. Prosthetic aspects and patient satisfaction with two-implant-retained mandibular overdentures: a 10-year randomized clinical study. Int J Prosthodont. 2004;17:401-10.

48. Yunus N, Saub R, Taiyeb Ali TB, Salleh NM, Baig MR. Patient-based and clinical outcomes of implant telescopic attachment-retained mandibular overdentures: a 1-year longitudinal prospective study. Int $\mathrm{J}$ Oral Maxillofac Implants. 2014;29:1149-56.
49. Karkazis H. EMG activity of the masseter muscle in implant supported overdenture wearers during chewing of hard and soft food. J Oral Rehabil. 2002;29:986-91.

50. Mericske-Stern RD, Taylor TD, Belser U. Management of the edentulous patient. Clin Oral Implants Res. 2000;11 Suppl 1:108-25.

51. Lachmann S, Kimmerle-Muller E, Gehring K, Axmann D, Gomez-Roman G, Watzek G, et al. A comparison of implant-supported, bar- or ball-retained mandibular overdentures: a retrospective clinical, microbiologic, and immunologic study of 10 edentulous patients attending a recall visit. Int J Prosthodont. 2007;20:37-42. 